\title{
Contagious Yawning and the Frontal Lobe: An fMRI Study
}

\author{
Fatta B. Nahab ${ }^{*}$, Noriaki Hattori, Ziad S. Saad, and Mark Hallett \\ Human Motor Control Section, Medical Neurology Branch, National Institutes of Neurological \\ Disorders and Stroke, National Institutes of Health, Bethesda, Maryland
}

\begin{abstract}
We conducted a slow event-related fMRI experiment with naïve subjects' passively viewing yawn and various other control videos along with correlative behavioral testing. Specifically associated with the viewing of the contagious yawn was an area of activation in the ventromedial prefrontal cortex. These findings suggest a role for the prefrontal cortex in the processing of contagious yawning, while demonstrating a unique automaticity in the processing of contagious motor programs which take place independently of mirror neuron networks.
\end{abstract}

\section{Keywords}

contagion; fMRI; motor program; urge; ventromedial prefrontal cortex; yawning

\section{INTRODUCTION}

Yawning is a primitive yet complex stereotyped motor response requiring the concerted activity of facial, oral, laryngeal, pharyngeal, thoracic, and abdominal muscles. In humans, yawning may occur spontaneously, as commonly seen with infants, or can be induced by an internal stimulus (e.g. thinking about yawning) or an external stimulus (e.g. viewing someone yawn) referred to as the contagion. [Provine, 2005] The act of spontaneous yawning is present across many species, though its function remains unclear. Conversely, contagious yawning (CY) has only been reported in chimpanzees [Anderson et al., 2004] and humans [Baenninger, 1987; Lehmann, 1979; Smith, 1999], suggesting a higher level of complexity. Furthermore, yawning by contagion likely represents only a few motor programs, such as contagious laughter [Provine, 1996], which may be involuntarily induced by external or internal (in the case of yawning) stimuli, which have been well described. [Provine and Hamernik, 1986] Despite numerous theories posited, the underlying etiology and neurobiology of these contagious motor programs remain unclear. Current hypotheses on the evolution of CY center on its potential role in social interaction, communication, and the development of empathy. [Gallese et al., 2004; Lehmann, 1979; Platek et al., 2003, 2005]. 
Recent neuroimaging studies of CY, using blood oxygen level dependent functional magnetic resonance imaging (BOLD-fMRI), have shown inconsistent regions of activation. Noting that experimental paradigms differed slightly, the finding of posterior cingulate and precuneus activations by Platek et al. [2005] suggests that CY involves theory of mind (ToM) or empathy networks, whereas a study by Schurmann et al. [2005] found right superior temporal sulcus (STS) activation. Both studies also noted a lack of activation, during $\mathrm{CY}$, in mirror neuron areas such as the inferior frontal cortices when compared with similar noncontagious motor acts which did activate mirror neuron areas. The absence of significant activations in mirror neuron areas suggests that highly stereotyped motor patterns, like CY, do not require true imitation and would therefore not activate mirror neurons.

On the basis of these intriguing findings, we sought to better define the brain regions activated while subjects viewed yawn videos when compared with areas activated while viewing similar noncontagious facial actions in an ecologically valid paradigm. We hypothesized that the viewing of noncontagious facial analogues to yawning would activate mirror neurons, whereas the viewing of contagious yawns would not.

\section{SUBJECTS AND METHODS}

\section{Stimuli}

Single video clips were recorded showing an unfamiliar actor performing four facial expressions: yawning, gaping, coughing, and a "blank" expressionless face with limited blinking (see Fig. 1). The blank face and cough stimuli served to control for facial perception and visual motion, whereas the gape action involved the actor opening the mouth wide then closing with similar timing to a yawn but while maintaining the eyes wide open and having a more robotic appearance. Gape thus, mimicked all aspects of facial movement, complexity, and timing associated with yawning, without conveying the behavioral or emotional components of yawning.

Video durations were $4 \mathrm{~s}$ for all clips and had a 12-s interstimulus interval to allow for the delayed hemodynamic response to return toward baseline. We selected this yawn duration which was shorter than that employed by previous studies [Platek et al., 2005, $7 \mathrm{~s}$;

Schürmann et al., $200524 \mathrm{~s}$ for two consecutive clips] to increase the total number of stimulus repetitions within the confines of a scan session. This shorter stimulus duration took into consideration the work of Provine [1986] showing the mean yawn duration is $5.9 \mathrm{~s}$ with a range of 3.5-11.2 s and which noted no link between yawn frequency and duration. A baseline signal was established by having subjects fixate on a white cross in the center of a neutral gray screen. We chose a slow event-related design, because we were concerned about the potential for either response habituation or potentiation, which may have been more likely in both block and fast event-related designs, due to prolonged stimulus durations or more frequent repetitions, respectively. The timing we selected thus allowed the display of a complete yawn cycle, while minimizing these additional potential confounds. The four stimuli were pseudorandomly presented 10 times per run, and there were two runs per session which were separated temporally by $1-2$ min. Videos were projected using Presentation version 9.0 (Neurobehavioral Systems; Albany, CA). 


\section{Subjects}

Eighteen healthy right-handed subjects (18-48 years of age, mean age \pm SD: $29.5 \pm 9.3$; nine females) participated in this study. All subjects underwent general medical screening and provided written informed consent in compliance with the Institutional Review Board of the National Institute of Neurological Disorders and Stroke. We excluded all subjects using dopaminergic agonists (including nicotine) or antagonists to avoid a potential confound associated with variable yawn susceptibilities. Subjects were also instructed to abstain from caffeine and alcohol for $48 \mathrm{~h}$ before scanning.

Because we sought to study the contagiousness of yawning in relatively naïve subjects, participants were told the aim of the study was to investigate the brain responses associated with the viewing of various facial expressions. The instructions that subjects received about the experiment were to simply view the stimuli with full attention and to avoid gross head and face movements. This was meant to minimize the chance subjects would realize the purpose of this experiment and subsequently develop a spontaneous internal urge to yawn. However, we were concerned about the susceptibility-induced magnetic field changes which may arise due to tongue or jaw movements [Birn et al., 1998] that would accompany yawning. Subjects were thus constrained with the use of VacFix vacuum cushions (Par Scientific; Houston, TX) that enclosed the head and wrapped around the chin. Before positioning and scanning, subjects were reminded to attend the stimuli and avoid facial and head movements.

\section{Image Acquisition and Analysis}

Structural and functional images were acquired with a 3-T magnetic resonance imaging (MRI) scanner (Signa, General Electric; Milwaukee, WI) using a standard head coil. Functional imaging was performed using a gradient-echo echo-planar pulse sequence $(64 \times$ 64 matrix, repetition time $[\mathrm{TR}]=2000 \mathrm{~ms}$, time to echo $[\mathrm{TE}]=30 \mathrm{~ms}, \mathrm{FOV}=24 \mathrm{~cm}$, flip angle $[\mathrm{FA}]=908)$. Whole-brain coverage was obtained with 25 axial slices $(5 \mathrm{~mm}$ thickness; $1 \mathrm{~mm}$ spacing; in-plane resolution $=3.75 \times 3.75 \mathrm{~mm}^{2}$ ). A total of 330 EPI image volumes were acquired for each of the two runs. The first five volumes of each run, collected before equilibrium magnetization was reached, were discarded before analysis. High resolution anatomical images (128 axial slices, $1.3 \mathrm{~mm}$ thickness) were obtained using a standard MPRAGE sequence $(256 \times 256$ matrix, $\mathrm{TR}=8.096 \mathrm{~ms}, \mathrm{TE}=3.22 \mathrm{~ms}, \mathrm{FOV}=24$ $\mathrm{cm}$, Phase FOV $=0.81, \mathrm{FA}=12^{\circ}$ ) to serve as an anatomical reference for spatial normalization.

\section{Imaging Data Analysis}

Image processing and analysis were performed with the AFNI software package. [Cox, 1996; Cox and Hyde, 1997; Saad et al., 2006] The EPI and anatomical datasets were converted from DICOM format to AFNI's native 3D and 4D formats. EPI time series data were corrected for slice timing offset. A six-parameter rigid body inter and intra-session motion correction was performed, whereby volumes in the EPI scans were registered to the last EPI volume, which was collected before the high-resolution MPRAGE scan. EPI time series data were smoothed using a 6-mm FWHM isotropic Gaussian kernel to minimize the anatomical variability among individual subject maps in generating group maps. The data 
was scaled by dividing voxel signal intensity by the mean intensity at that voxel for each session and multiplying the result by 100 . The resulting regression coefficients thus represent a percent signal change from the mean. The 3D anatomical and 4D time series datasets were then transformed to Talairach standard space [Talairach and Tournoux, 1988] with a resolution of $3 \times 3 \times 3 \mathrm{~mm}^{3}$.

To model the hemodynamic response functions for linear regression analysis, we convolved the timing of each stimulus class with a g-variate function that approximated the BOLD response. [Cohen, 1997] For each voxel, the fixed shape analysis resulted in a single response amplitude for each stimulus class. In addition to the regressors which modeled the stimulus response, we included regressors to model motion residuals and baseline drifts using quadratic polynomials in time for each run. The statistical correction for multiple comparisons was set by rejecting spatial clusters smaller than what would be expected by chance using Monte-Carlo simulations [Forman et al., 1995], given a voxel-wise falsepositive level of $P<0.001$ which resulted in a corrected $P<0.05$ (minimum cluster size of 13 voxels, $351 \mu \mathrm{l})$.

For the group analysis, we analyzed individual subject regression coefficients using a twoway ANOVA with the four stimulus classes as fixed effects and subject as random effects. This analysis is also commonly termed a oneway within subject ANOVA.

\section{Behavioral Data}

Subjects were required to complete a postscan questionnaire consisting of seven questions. The binary questionnaire asked whether subjects yawned when seeing, reading, or thinking about yawns in general as well as their urge when viewing our experiment stimulus videos. Additionally, we asked whether the subject actually yawned during the experiment, the timing of the urge (immediate/ delayed) and whether repeated presentations of the stimulus made them more or less likely to experience the urge.

\section{RESULTS}

\section{Behavioral Data}

Seventeen of 18 subjects reported having a contagious urge to yawn in general. Of these subjects, eight reported experiencing the urge to yawn and suppressing it when viewing the yawn stimulus during the experiment compared with two subjects who reported an urge to yawn while viewing the nonyawn stimuli $(P=0.046)$. Seven subjects indicated that their urge to yawn diminished as the number of stimulus presentations increased. No subjects reported overtly yawning during the runs. A review of the EPI data, using AFNI in video mode, found no gross motion artifacts involving brain areas close to the jaw and face. Furthermore, the tell-tale signs of oral motion-induced artifacts at skull-air and skull-brain interfaces were also not present.[Birn et al., 1998] Regardless of the potential for more subtle artifacts related to minimal jaw motion, it should be noted that our areas of interest are distant from these regions and unlikely to have a significant impact. 


\section{Functional MRI Data}

The main effects analysis for each stimulus versus baseline showed typical activation of the primary visual cortex for all conditions (see Fig. 2). Dynamic stimuli such as cough, gape, and yawn also showed activations in visual motion areas (V5/MT). For our cough and gape stimuli, we found common activations in right inferior frontal cortex and right STS. The gape condition showed a number of additional activations, including the bilateral ventral premotor areas, the parahippocampal gyrus near the ventral posterior cingulate (BA 23), and pre-SMA. The yawn condition showed similar activations as the gape condition with the addition of the ventromedial prefrontal cortex and the absence of other areas which were only present at subthreshold levels. Table I provides a summary of all significant activations for the various contrasts. For our contrast of interest (Yawn-Gape), we found a significant difference only in the region of the ventromedial prefrontal cortex (see Fig. 3).

To extend these findings, we also looked at the signal amplitude of the BOLD response to ensure that our findings were not an artifact of contrasting positive activations and negative activations (deactivations). To ascertain how the data varied with each stimulus class, we selected a peak voxel maximum in the ventromedial prefrontal cortex (vmPFC; $x=1.5, y=$ $25.5, z=-9.5)$ and a control peak voxel maximum in the right area V5/MT $(x=44, y=-71, z$ $=8$ ) activation for comparison. We then looked at the BOLD response amplitudes across subjects for each stimulus class in the two areas (see Fig. 4). Activations in visual areas showed a trend consistent with the amount of visual motion in the corresponding stimulus, and the yawn and gape stimuli were not statistically different $(P=0.064)$. Additionally, we found activation in the vmPFC that was unique to our yawn stimulus. Comparisons of the vmPFC activation showed significant differences between both the yawn and gape amplitudes $(P=0.002)$ and the yawn and cough amplitudes $(P=0.020)$, whereas yawn and blank face activations only showed a trend toward significance $(P=0.072)$.

Although we are not aware of any literature suggesting that the ventromedial prefrontal cortex may differentially activate based on variable amounts of visual motion, we wanted to ensure that the yawn activations in this region could not be explained by the difference in visual motion of the various stimuli. After normalizing the signal amplitudes in the vmPFC by the activations in the V5/MT region, we found the same trends as our analysis without normalization (see Fig. 4).

All neuroimaging-based activations associated with studies of CY reflect the potential confound of yawn suppression. To explore whether our vmPFC activation was differentially active in our subgroup of subjects who reported suppressing their yawn, we conducted a post hoc subgroup $t$-test between subjects who suppressed yawning $(n=8)$ and subjects who denied suppression $(n=10)$ during the experiment. Areas which were more active $(P<0.05$, corrected) in the suppression group were the left pre-central gyrus $(\mathrm{Z}=3.09 ; x=-55, y=$ $-24.5, z=41.5$; cluster volume $=891 \mu \mathrm{l})$, left anterior cingulate $(\mathrm{Z}=2.69 ; x=-13.5, y=$ $37.5, z=2.5 ; 567 \mu \mathrm{l})$, right cerebellum $(\mathrm{Z}=2.76 ; x=7.5, y=-61.5, z=-27.5 ; 378 \mu \mathrm{l})$, and right cuneus $(Z=3.49 ; x=19.5, y=-88.5, z=29.5 ; 378 \mu \mathrm{l})$. No clusters were more active in the nonsuppression group, and we found no differential activation in the vmPFC even when we lowered the threshold. 


\section{DISCUSSION}

To our knowledge, the finding of ventromedial prefrontal cortex (vmPFC; BA11) activation associated with the urge to yawn by a contagion has not been previously reported. Most commonly, the vmPFC has been shown to assign relative value to different options, thereby weighting or biasing future choices and minimizing decision making time. [Bechara et al., 1999, 2000; Elliott et al., 1999; Fellows and Farah, 2007; Northoff et al., 2006] Additional studies have implicated the vmPFC in empathic processing. Eslinger [1998] noted that patients sustaining injuries to the prefrontal cortex developed impairments in empathic processing, thereby limiting their capacity to process emotional information. Similarly, Shamay-Tsoory et al. used empathy scores and ToM tasks to study brain injured patients with frontal lesions, posterior lesions, and controls to assess whether changes in empathic processing correlated with particular structural lesions. They found activity in the right ventromedial prefrontal cortex to correlate highly with impairments on various empathy measures. [Shamay-Tsoory et al., 2003] Functional imaging studies have also implicated vmPFC and orbitofrontal regions in ToM tasks. [Baron-Cohen et al., 1994; Calder et al., 2002; Fletcher et al., 1995; Gallagher et al., 2000; Goel et al., 1995].

Our finding of vmPFC activation therefore suggests that this area may be the prefrontal component of the empathy network, which has been previously implicated in CY. In addition to the finding of vmPFC activation associated with $\mathrm{CY}$, our results provide a basis on which to integrate the discrepant findings of Platek et al. [2005] and Schur-mann et al. [2005]. We found similar activation of parahippocampal/ventral posterior cingulate areas identified by Platek et al., although we found no significant activations in the precuneus or thalamus. These regional similarities did not, however, differ between our yawn and gape conditions. Our paradigm also showed activation of what has been indirectly shown to be the human mirror neuron system [Buccino et al., 2001; Carr et al., 2003; Leslie et al., 2004; Rizzolatti and Craighero, 2004], including inferior frontal gyrus and STS in both the cough and gape conditions, in addition to right ventral premotor, pre-SMA, and inferior parietal lobule in the gape condition. When contrasting yawn vs. gape, we found no significant mirror neuron activations, because this region was active in both conditions as well as the cough condition at subthreshold levels. These findings thereby support the results of Schurmann et al. [2005] and further suggest that although the right premotor cortex may be involved with the processing of facial expressions, it is not unique to yawning and is not likely to be the primary region underlying contagious motor programs.

The mechanism by which a contagion releases a yawn remains unclear. [Provine, 2005] The involvement of vmPFC in the urge to yawn by contagion is however underscored by this region's association with emotional processing of internal and external stimuli and representation of emotional responses. [Bush et al., 2000; Lane et al., 1997; Posner, 1995] Furthermore, although the motor act of yawning does not require cortical control, our findings suggest that the cortex may be required for transmittal of a contagious motor program like yawning. The vmPFC thus appears an ideal region for processing and "releasing" contagious motor programs. It may also help to explain how the urge to yawn by a contagion could be unique to humans and possibly nonhuman primates, although spontaneous yawning is present even in lower animals. This proposed role of the vmPFC 
may also provide insights to explain the early observations of Piaget [1951] and the recent work of Anderson and Meno [2003] noting CY did not develop in children below 5 years of age. It remains unclear, however, what developmental or biological milestones (e.g., axonal myelination, synaptic plasticity, empathic processing) must take place in the child's brain before motor programs can be released via a contagion. These findings are in contradistinction to the paradoxical innate capacity to imitate which is present in healthy human neonates. [Nagy, 2006] Further studies are needed to identify whether contagious and noncontagious motor programs are processed by different neural correlates in order to develop a unified framework, which accounts for both the current view that CY has evolved as a form of empathic modeling and that the mirror neuron system is the primary substrate for experiential or empathic understanding of others.

Although our findings identify a new component to the network underlying CY, we acknowledge that only eight (47\%) of our 17 naïve subjects, who reported experiencing CY in general, reported feeling a similar urge during the experiment and suppressing it. For comparison, Provine [1989] reported subjects' yawn response rates of 55\% during the viewing of a 5 min series of 30 yawns versus $21 \%$ who yawned while viewing a series of smiles. With regard to the potential confound introduced by suppression of yawning which exists in similar experiments, our post hoc results suggest that the vmPFC was not associated with suppression and also identifies regions such as the anterior cingulate, which are known to be active during cognitive and motor suppression [Bush et al., 2000; Krams et al., 1998].

Based on these collective data, the highly evolved vmPFC appears a valid brain region for the processing and release of contagious motor programs such as yawning. Taken together, these data suggest that the urge to yawn via contagion, unlike other noncontagious facial expressions, does not take place through a process of imitation or mimicry, rather the primitive motor program is "released" by the cortex and is carried out through wellcharacterized brainstem and subcortical mechanisms.

\section{Acknowledgments}

The authors are grateful to Richard Reynolds and Dr. Gang Chen for their technical expertise and assistance in the data analysis.

Contract grant sponsor: Intramural Division of the National Institute of Neurological Disorders and Stroke, National Institutes of Health

\section{REFERENCES}

Anderson JR, Meno P. Psychological influences on yawning in children. Curr Psychol Lett. 2003; 11 Available at: http://cpl.revues.org/document390.html.

Anderson JR, Myowa-Yamakoshi M, Matsuzawa T. Contagious yawning in chimpanzees. Proc Biol Sci. 2004; 271(Suppl 6):S468-S470. [PubMed: 15801606]

Baenninger R. Some comparative aspects of yawning in Betta splendens, Homo sapiens, Panthera leo, and Papio sphinx. J Comp Psychol. 1987; 101:349-354.

Baron-Cohen S, Ring H, Moriarty J, Schmitz B, Costa D, Ell P. Recognition of mental state terms. Clinical findings in children with autism and a functional neuroimaging study of normal adults. $\mathrm{Br} \mathrm{J}$ Psychiatry. 1994; 165:640-649. [PubMed: 7866679] 
Bechara A, Damasio H, Damasio AR, Lee GP. Different contributions of the human amygdala and ventromedial prefrontal cortex to decision-making. J Neurosci. 1999; 19:5473-5481. [PubMed: 10377356]

Bechara A, Tranel D, Damasio H. Characterization of the decision-making deficit of patients with ventromedial prefrontal cortex lesions. Brain. 2000; 123(Part 11):2189-2202. [PubMed: 11050020]

Birn RM, Bandettini PA, Cox RW, Jesmanowicz A, Shaker R. Magnetic field changes in the human brain due to swallowing or speaking. Magn Reson Med. 1998; 40:55-60. [PubMed: 9660553]

Buccino G, Binkofski F, Fink G, Fadiga L, Fogassi L, Gallese V, Seitz R, Zilles K, Rizzolatti G, Freund HJ. Action observation activates premotor and parietal areas in a somatotopic manner: An fMRI study. Eur J Neurosci. 2001; 13:400-404. [PubMed: 11168545]

Bush G, Luu P, Posner MI. Cognitive and emotional influences in anterior cingulate cortex. Trends Cogn Sci. 2000; 4:215-222. [PubMed: 10827444]

Calder AJ, Lawrence AD, Keane J, Scott SK, Owen AM, Christoffels I, Young AW. Reading the mind from eye gaze. Neuropsychologia. 2002; 40:1129-1138. [PubMed: 11931917]

Carr L, Iacoboni M, Dubeau MC, Mazziotta JC, Lenzi GL. Neural mechanisms of empathy in humans: A relay from neural systems for imitation to limbic areas. Proc Natl Acad Sci USA. 2003; 100:5497-5502. [PubMed: 12682281]

Cohen MS. Parametric analysis of fMRI data using linear systems methods. Neuroimage. 1997; 6:93103. [PubMed: 9299383]

Cox RW. AFNI: Software for analysis and visualization of functional magnetic resonance neuroimages. Comput Biomed Res. 1996; 29:162-173. [PubMed: 8812068]

Cox RW, Hyde JS. Software tools for analysis and visualization of fMRI data. NMR Biomed. 1997; 10:171-178. [PubMed: 9430344]

Elliott R, Rees G, Dolan RJ. Ventromedial prefrontal cortex mediates guessing. Neuropsychologia. 1999; 37:403-411. [PubMed: 10215087]

Eslinger PJ. Neurological and neuropsychological bases of empathy. Eur Neurol. 1998; 39:193-199. [PubMed: 9635468]

Fellows LK, Farah MJ. The role of ventromedial prefrontal cortex in decision making: Judgment under uncertainty or judgment per se? Cereb Cortex. 2007; 17:2669-2674. [PubMed: 17259643]

Fletcher PC, Happe F, Frith U, Baker SC, Dolan RJ, Frackowiak RS, Frith CD. Other minds in the brain: A functional imaging study of "theory of mind" in story comprehension. Cognition. 1995; 57:109-128. [PubMed: 8556839]

Forman SD, Cohen JD, Fitzgerald M, Eddy WF, Mintun MA, Noll DC. Improved assessment of significant activation in functional magnetic resonance imaging (fMRI): Use of a cluster-size threshold. Magn Reson Med. 1995; 33:636-647. [PubMed: 7596267]

Gallagher HL, Happe F, Brunswick N, Fletcher PC, Frith U, Frith CD. Reading the mind in cartoons and stories: An fMRI study of 'theory of mind' in verbal and nonverbal tasks. Neuropsychologia. 2000; 38:11-21. [PubMed: 10617288]

Gallese V, Keysers C, Rizzolatti G. A unifying view of the basis of social cognition. Trends Cogn Sci. 2004; 8:396-403. [PubMed: 15350240]

Goel V, Grafman J, Sadato N, Hallett M. Modeling other minds. Neuroreport. 1995; 6:1741-1746. [PubMed: 8541472]

Krams M, Rushworth MF, Deiber MP, Frackowiak RS, Passingham RE. The preparation, execution and suppression of copied movements in the human brain. Exp Brain Res. 1998; 120:386-398. [PubMed: 9628425]

Lane RD, Fink GR, Chau PM, Dolan RJ. Neural activation during selective attention to subjective emotional responses. Neuroreport. 1997; 8:3969-3972. [PubMed: 9462476]

Lehmann H. Yawning: A homeostatic reflex and its psychological significance. Bull Meninger Clin. 1979; 43:123-136.

Leslie KR, Johnson-Frey SH, Grafton ST. Functional imaging of face and hand imitation: Towards a motor theory of empathy. Neuroimage. 2004; 21:601-607. [PubMed: 14980562]

Nagy E. From imitation to conversation: The first dialogues with human neonates. Infant Child Dev. 2006; 15:223-232. 
Northoff G, Grimm S, Boeker H, Schmidt C, Bermpohl F, Heinzel A, Hell D, Boesiger P. Affective judgment and beneficial decision making: Ventromedial prefrontal activity correlates with performance in the Iowa Gambling Task. Hum Brain Mapp. 2006; 27:572-587. [PubMed: 16372256]

Piaget, J. Play, Dreams and Imitation in Childhood. Norton; New York: 1951.

Platek SM, Critton SR, Myers TE, Gallup GG. Contagious yawning: The role of self-awareness and mental state attribution. Brain Res Cogn Brain Res. 2003; 17:223-227. [PubMed: 12880893]

Platek SM, Mohamed FB, Gallup GG Jr. Contagious yawning and the brain. Brain Res Cogn Brain Res. 2005; 23:448-452. [PubMed: 15820652]

Posner, MI. Attention in cognitive neuroscience: An overview.. In: Gazzaniga, MS., editor. The Cognitive Neurosciences. MIT Press; Cambridge, MA: 1995. p. 615-624.

Provine, RR. Contagious yawning and laughter: Significance for sensory feature detection, motor pattern generation, imitation, and the evolution of social behavior.. In: Heyes, CM.; Galef, BG., editors. Social Learning in Animals: The Roots of Culture. Academic Press; New York: 1996. p. 179-208.

Provine RR. Yawning as a stereotyped action pattern and releasing stimulus. Ethology. 1986; 72:109122.

Provine RR. Faces as releasers of contagious yawning: An approach to face detection using normal human subjects. Bull Psychon Soc. 1989; 27:211-214.

Provine RR. Yawning. Am Sci. 2005; 93:532-539.

Provine RR, Hamernik HB. Yawning: Effects of stimulus interest. Bull Psychon Soc. 1986; 24:437438.

Rizzolatti G, Craighero L. The mirror-neuron system. Annu Rev Neurosci. 2004; 27:169-192. [PubMed: 15217330]

Saad ZS, Chen G, Reynolds RC, Christidis PP, Hammett KR, Bellgowan PS, Cox RW. Functional imaging analysis contest (FIAC) analysis according to AFNI and SUMA. Hum Brain Mapp. 2006; 27:417-424. [PubMed: 16568421]

Schurmann M, Hesse MD, Stephan KE, Saarela M, Zilles K, Hari R, Fink GR. Yearning to yawn: The neural basis of contagious yawning. Neuroimage. 2005; 24:1260-1264. [PubMed: 15670705]

Shamay-Tsoory SG, Tomer R, Berger BD, Aharon-Peretz J. Characterization of empathy deficits following prefrontal brain damage: The role of the right ventromedial prefrontal cortex. J Cogn Neurosci. 2003; 15:324-337. [PubMed: 12729486]

Smith EO. Yawning: An evolutionary perspective. Hum Evol. 1999; 14:191-198.

Talairach, J.; Tournoux, P. Co-Planar Stereotaxic Atlas of the Human Brain. Thieme Medical Publishers; New York: 1988. 


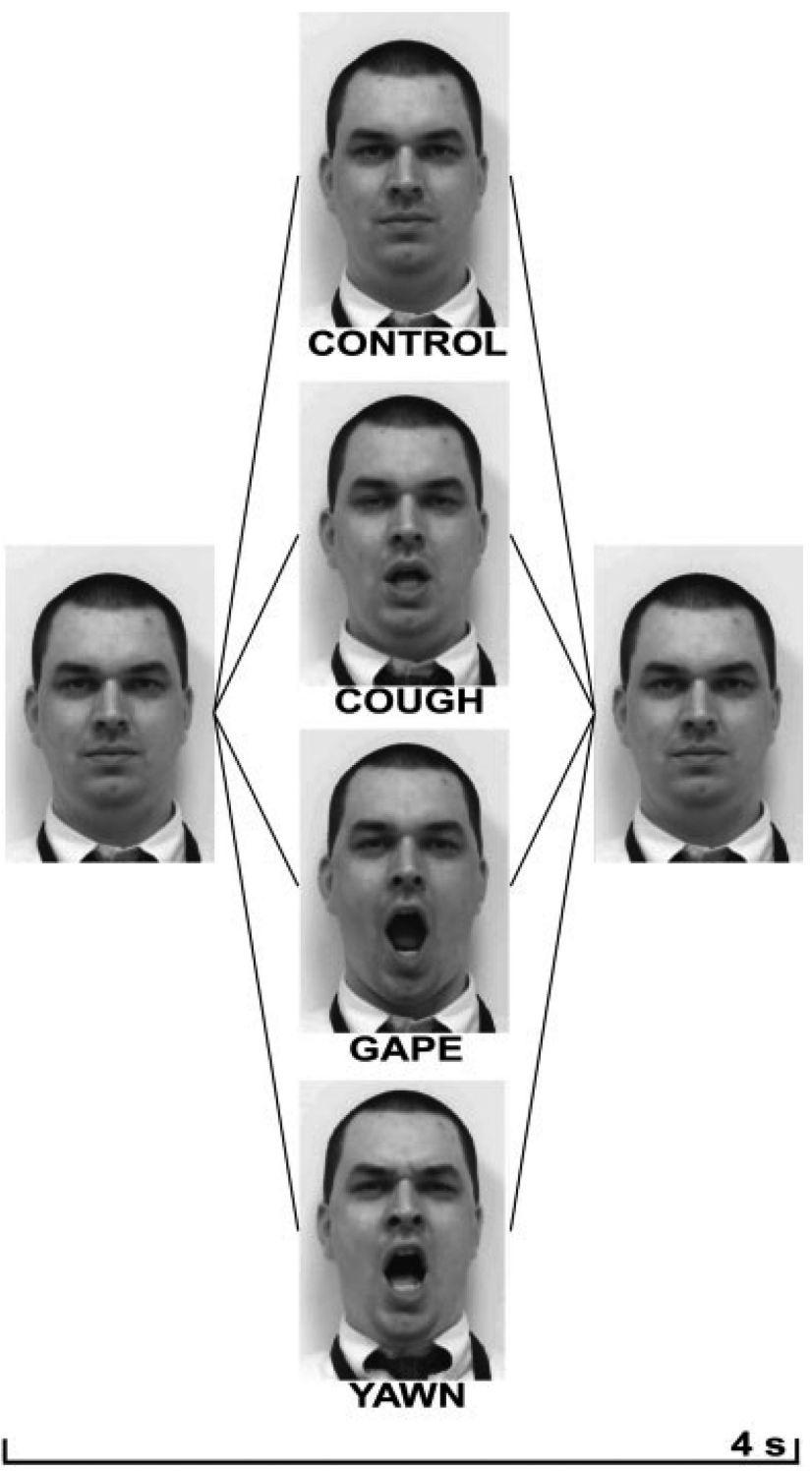

Figure 1.

Representative video frames of each stimulus demonstrating blank face, cough, gape, and blank face conditions over time. 


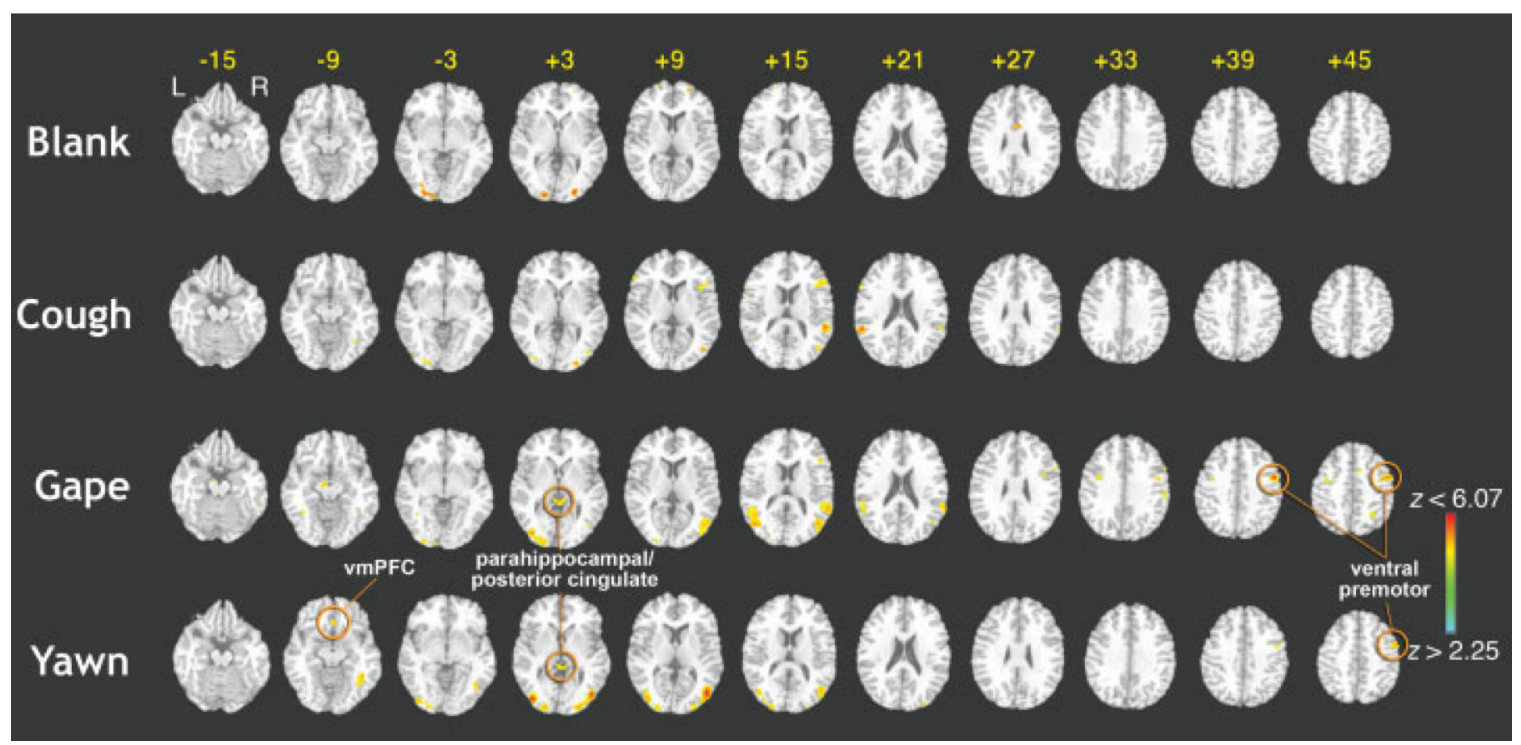

Figure 2.

Statistical parametric maps showing regions of BOLD activation for each stimulus class versus rest. Results showing the significant mean activations for each stimulus class versus rest condition, superimposed on a standard T1-weighted brain in Talairach space. Color bar represents the statistical $\mathrm{z}$-values above the statistical threshold ( $P \leq 0.05$, corrected). All images are shown in neurological convention. 


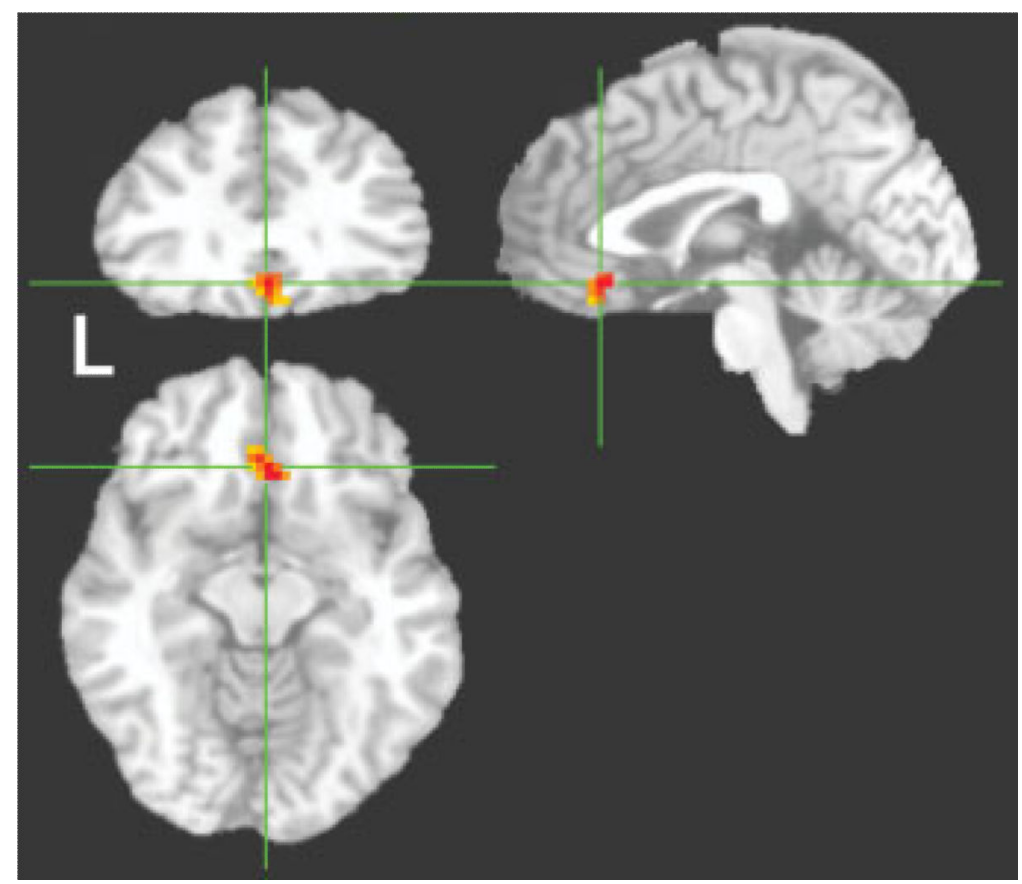

Figure 3.

Yawn-Gape activation. Results of Yawn vs. Gape contrast showing significant $(P \leq 0.05$, corrected) activation in the ventromedial pre-frontal cortex (local cluster maximum center of mass in Talairach coordinates at $x=1.5, y=25.5, z=29.5 ; \mathrm{Z}=9.5 ; \mathrm{Z}_{\max }=3.95$ ). 
Group Mean Coefficients for Conditions vs. Baseline Fixation

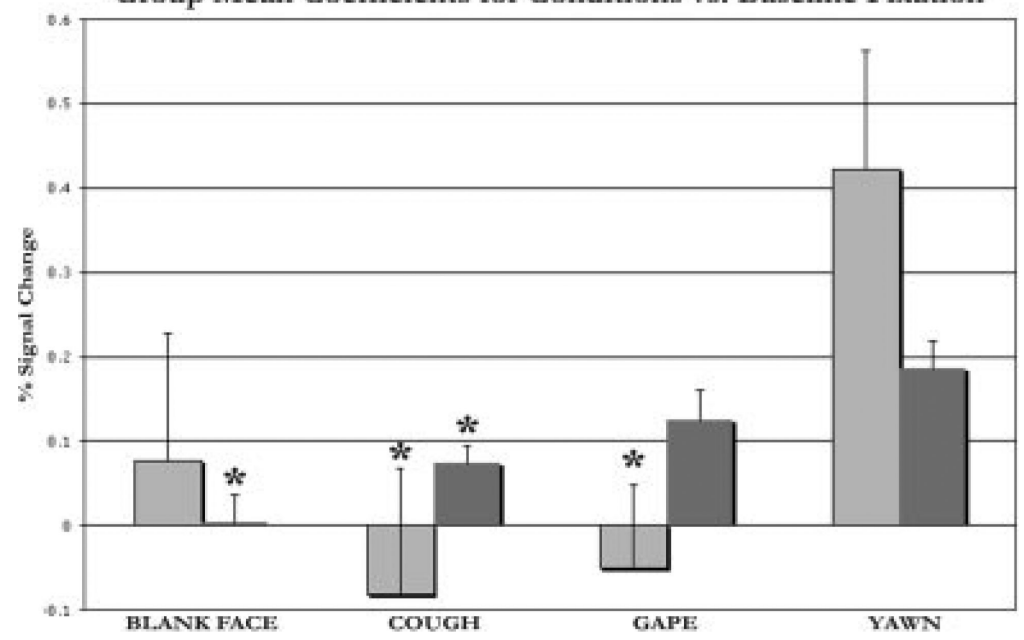

Figure 4.

Mean BOLD responses for each stimulus class in the ventrome-dial prefrontal cortex and area V5/MT. The mean BOLD signal amplitude changes for each stimulus class versus rest are shown in two regions: ventromedial prefrontal cortex (light gray bars) and right V5/MT (dark gray bars). Asterisks represent a signifi-cant difference $(P \leq 0.05)$ from the yawn stimulus in the region of interest. Error bars show standard deviations. 


\section{TABLE I}

Summary of BOLD activations for various contrasts

\begin{tabular}{|c|c|c|c|c|c|c|}
\hline \multirow[b]{2}{*}{ Contrast } & \multirow[b]{2}{*}{ Anatomic structure } & \multirow[b]{2}{*}{ Cluster volume $(\mu \mathrm{L})$} & \multicolumn{3}{|c|}{ Cluster coordinates (COM) } & \multirow[b]{2}{*}{$Z$-max } \\
\hline & & & $x$ & $y$ & $z$ & \\
\hline \multirow[t]{5}{*}{ Control vs. baseline } & Left middle occipital gyrus & 2,268 & -19.5 & -91.5 & -0.5 & 4.23 \\
\hline & Right middle occipital gyrus & 945 & 22.5 & -85.5 & 2.5 & 3.41 \\
\hline & Left superior frontal gyrus & 621 & -16.5 & 64.5 & 14.5 & 3.05 \\
\hline & Right superior frontal gyrus & 567 & 25.5 & 55.5 & 8.5 & 3.00 \\
\hline & Right anterior cingulate & 540 & 4.5 & 4.5 & 29.5 & 3.03 \\
\hline \multirow[t]{11}{*}{ Cough vs. baseline } & Right inferior frontal gyrus & 2,403 & 46.5 & 25.5 & 11.5 & 3.48 \\
\hline & Right STS & 1,998 & 52.5 & -37.5 & 14.5 & 4.15 \\
\hline & Left STS & 1,377 & -55.5 & -40.5 & 20.5 & 4.82 \\
\hline & Left middle occipital gyrus & 1,350 & -37.5 & -82.5 & -0.5 & 3.72 \\
\hline & Left inferior frontal gyrus & 1,296 & -58.5 & 19.5 & 20.5 & 3.50 \\
\hline & Right MT & 1,215 & 43.5 & -70.5 & 8.5 & 3.62 \\
\hline & & 567 & 49.5 & 7.5 & -24.5 & 3.48 \\
\hline & Right middle occipital gyrus & 567 & 25.5 & -91.5 & 2.5 & 4.00 \\
\hline & Right temporal pole & 459 & 28.5 & 28.5 & -27.5 & 5.34 \\
\hline & Brainstem & 378 & 1.5 & -28.5 & -42.5 & 3.82 \\
\hline & Right fusiform gyrus & 378 & 34.5 & -58.5 & -9.5 & 3.07 \\
\hline \multirow[t]{15}{*}{ Gape vs. baseline } & Left middle occipital gyrus & 4,698 & -43.5 & -67.5 & 14.5 & 4.20 \\
\hline & Right middle occipital gyrus & 4,050 & 43.5 & -67.5 & 14.5 & 4.14 \\
\hline & Left middle occipital gyrus & 3,888 & -37.5 & -79.5 & 2.5 & 4.53 \\
\hline & Right ventral premotor & 3,699 & 49.5 & -1.5 & 38.5 & 6.08 \\
\hline & Right STS & 2,646 & 58.5 & -43.5 & 17.5 & 4.22 \\
\hline & Left ventral premotor & 1,377 & -37.5 & -4.5 & 35.5 & 3.01 \\
\hline & Parahippocampal gyrus & 1,161 & 1.5 & -37.5 & 2.5 & 4.22 \\
\hline & Left hippocampus & 783 & -10.5 & -13.5 & -9.5 & 3.40 \\
\hline & Right medial frontal gyrus & 729 & 7.5 & 7.5 & 47.5 & 3.69 \\
\hline & Right inferior frontal gyrus & 675 & 43.5 & 22.5 & 14.5 & 2.91 \\
\hline & Right postcentral gyrus & 675 & 55.5 & -22.5 & 32.5 & 2.87 \\
\hline & Left superior frontal gyrus & 621 & -16.5 & -16.5 & 74.5 & 3.60 \\
\hline & Right inferior parietal lobule & 594 & 25.5 & -55.5 & 44.5 & 3.02 \\
\hline & Left fusiform gyrus & 459 & -37.5 & -49.5 & -6.5 & 3.27 \\
\hline & Right inferior temporal gyrus & 351 & 52.5 & -46.5 & -12.5 & 3.08 \\
\hline \multirow[t]{5}{*}{ Yawn vs. baseline } & Right middle occipital gyrus & 9,342 & 43.5 & -73.5 & 5.5 & 5.99 \\
\hline & Left middle occipital gyrus & 6,615 & -40.5 & -79.5 & 2.5 & 5.87 \\
\hline & Right ventral premotor & 1,107 & 52.5 & 1.5 & 44.5 & 4.54 \\
\hline & Parahippocampal gyrus & 837 & -1.5 & -34.5 & 2.5 & 4.17 \\
\hline & vmPFC & 459 & 1.5 & 28.5 & -9.5 & 3.48 \\
\hline \multirow[t]{2}{*}{ Gape vs. yawn } & Left postcentral gyrus & 3,213 & -31.5 & -34.5 & 65.5 & 3.21 \\
\hline & Right MT & 1,998 & 67.5 & -40.5 & -3.5 & 3.55 \\
\hline
\end{tabular}

Front Neurol Neurosci. Author manuscript; available in PMC 2014 June 02. 


\begin{tabular}{|c|c|c|c|c|c|c|}
\hline \multirow[b]{2}{*}{ Contrast } & \multirow[b]{2}{*}{ Anatomic structure } & \multirow[b]{2}{*}{ Cluster volume $(\mu \mathrm{L})$} & \multicolumn{3}{|c|}{ Cluster coordinates $(\mathrm{COM})$} & \multirow[b]{2}{*}{$Z$-max } \\
\hline & & & $x$ & $y$ & $z$ & \\
\hline & Left inferior temporal gyrus & 1,215 & -58.5 & -58.5 & -6.5 & 3.39 \\
\hline & Left parahippocampal gyrus & 1,053 & -10.5 & -10.5 & -12.5 & 3.23 \\
\hline & Left cingulate gyrus & 1,053 & -7.5 & -37.5 & 32.5 & 2.97 \\
\hline & Right cerebellum & 810 & 13.5 & -49.5 & -45.5 & 3.59 \\
\hline & Left cuneus & 702 & -1.5 & -85.5 & 29.5 & 3.07 \\
\hline & & 648 & -7.5 & -67.5 & 26.5 & 3.23 \\
\hline & Right postcentral gyrus & 648 & 52.5 & -22.5 & 35.5 & 2.74 \\
\hline & Left postcentral gyrus & 621 & -58.5 & -22.5 & 35.5 & 2.82 \\
\hline & Right cingulate gyrus & 567 & 10.5 & -40.5 & 32.5 & 2.68 \\
\hline & Left middle frontal gyrus & 567 & -25.5 & -1.5 & 56.5 & 3.01 \\
\hline & Left precentral gyrus & 513 & -40.5 & -13.5 & 23.5 & 2.75 \\
\hline & Left MT & 486 & -64.5 & -31.5 & -6.5 & 3.16 \\
\hline & Left superior frontal gyrus & 486 & -13.5 & 55.5 & 17.5 & 2.73 \\
\hline & Right middle frontal gyrus & 459 & 31.5 & 25.5 & 44.5 & 3.14 \\
\hline & Near right caudate nucleus & 432 & 1.5 & 7.5 & 8.5 & 3.29 \\
\hline & Right lingual gyrus & 405 & 16.5 & -79.5 & -12.5 & 2.95 \\
\hline Yawn vs. gape & vmPFC & 891 & 1.5 & 25.5 & -9.5 & 3.95 \\
\hline
\end{tabular}

Summary of all significant activations ( $p \leq 0.05$, corrected) for the main effects analyses and Yawn-Gape contrasts performed. Clusters are listed in order of their maximum $z$-value. Gray highlight shows contrast of interest.

Positive coordinate values signify: Right-anterior-superior.

COM, center of mass; MT, middle temporal gyrus; STS, superior temporal sulcus; vmPFC, ventromedial prefrontal cortex. 